\title{
Applying a Conceptual Mini Game for Supporting Simple Mathematical Calculation Skills: Students' Perceptions and Considerations
}

\author{
Chris T. Panagiotakopoulos \\ Department of Primary Education, University of Patras \\ University Campus 26504, Patras, Greece \\ Tel: +30-2610-997-907 E-mail: cpanag@upatras.gr
}

Received: March 4, 2010 Accepted: March 16, $2010 \quad$ doi:10.5430/wje.v1n1p3

\begin{abstract}
Mathematics is an area of study that particularly lacks student enthusiasm. Nevertheless, with the help of educational games, any phobias concerning mathematics can be considerably decreased and mathematics can become more appealing. In this study, an educational game addressing mathematics was designed, developed and evaluated by a sample of 33 students of the fifth grade of a primary school. Each student played the educational game "Playing with Numbers" (PwN), performing additions with integers, additions with decimals and multiplications with integers for a total of one hour, divided into four sessions. Next, the sample was asked to provide feedback regarding specific questions, and the analysis of the results showed that the PwN application is attractive and delivers usage. The attraction of the PwN game probably owes its success to its competitive element, as users are driven to achieve high scores. The PwN application was also found to be easy to use, and this made the challenge of achieving a high score more appealing, as success depended only on the cognitive skills of the user and not on any weaknesses or difficulties raised by the application itself. The findings of this study show that students would benefit from educational games and would be happy to work within an environment that motivated them and indirectly forced them to deal with mathematical operations while playing.
\end{abstract}

Keywords: Mini games, Educational games, Educational technology, Mathematics

\section{Introduction}

Nowadays, we are surrounded by technological and multimedia products in every aspect of our everyday lives. One of these products is digital games, which have seen a gradual increase in use over the last twenty years for multiple purposes (Jeong, Park, Ryu \& Lee, 2008). Digital games occupy an important part of most children’s leisure time and an important part of our culture as a whole (Kirriemuir \& McFarlane, 2004).

According to Siwek (2007), the digital games industry nowadays constitutes one of the most significant sectors of software business. Several new and emerging ICT technologies are used for the development of digital games. These technologies give new opportunities and improved features when compared with traditional ones, creating increased realism and enabling the production of interfaces that address a wide range of possible customers from different social groups (Illanas, Gallego, Satorre \& Llorens, 2008).

Today, digital games can be found in private environments (e.g. the home) in the form of online computer games, stand-alone computer games and console-based video games, or in public environments in the form of arcade games (Jeong, Park, Ryu \& Lee, 2008). They are generally considered to be a form of entertainment. Digital games can motivate players by providing them with appropriate levels of challenge, curiosity, control, and fantasy (Malone \& Lepper, 1987; Balasubramanian \& Wilson, 2005). Habgood (2007) argues that a digital game is "an interactive challenge on a digital platform, which is undertaken for entertainment”.

Throughout the literature, several classifications of digital games can be found that do not meet a general consensus among researchers. Taking into account the studies of Kirriemuir \& McFarlane (2004), Schiffler (2006), Felicia (2009), Kickmeier-Rust (2009), and Whitton (2010), we can classify digital games in the following seven categories:

- Action Games (interactive gameplay requiring fast reflexes and hand-eye coordination). Included in this category are reaction-based, platform, maze, shooting, fighting, racing and sport games.

- Role-Playing Games (interactive fantasy gameplay requiring planning). Research on this field led to the development of MMORPGs (Massive, Multiple, Online Role-Playing Games). 
- Strategy Games (requiring analytical thinking, reasoning and planning). These games formed the basis for the development of RTS (Real Time Strategy) type.

- Adventure Games (interactively experiencing narratives with cognitive/reasoning aspects).

- Simulation Games (replay real or fictitious situations).

- $\quad$ Puzzle Games (matching or constructive puzzles).

- Educational Games (games developed for educational purposes).

These seven categories often overlap, as a game may fall into more than one category. For instance, a game may belong to the category "Action" but be implemented as a simulation.

According to Hodgson, Man \& Leung (2010), the wisdom of using digital games for learning is debatable, because games are commonly perceived as tools for having fun. Although games can be effective learning environments, not all games are effective, nor are all games educational and beneficial for all learners or for all learning outcomes (Oblinger, 2006).

\section{Educational Games}

The last category of the classification of digital games (Educational Games) provided in the previous section, aims to teach through lively activities combining education with entertainment (Yanhong, Liming \& Lifang, 2010). This combination transforms the game into an effective tool for educational purposes, with elements such as immediate feedback, interactivity, and challenge (Annetta et al., 2006; Amr, 2007; Yusoff, 2010).

Many researchers and educators have noted the positive effects of educational games in thinking and learning, and as a result, many researchers have developed games for educational purposes in many fields (Oblinger, 2004; Virvou, Katsionis \& Manos, 2005; Amr, 2007; Pivec \& Kearney, 2007). Contemporary research indicates that educational games have the potential to improve learning (Srinivasan, Butler-Purry \& Pedersen, 2008) and to increase the likelihood that the desired learning outcomes will be achieved (Pivec \& Kearney, 2007). As noted by Graesser, Chipman, Leeming, and Biedenbach (2009), instead of learning about courses by reading a textbook, listening to a lecture, or interacting with a computer-based training system, the student could learn by playing an educational game that is successfully integrated with the curriculum. More specifically, educational games can improve learning because they:

- increase motivation (Garris, Ahlers \& Driskell, 2002; Lee \& Peng, 2006; Graesser, Chipman, Leeming \& Biedenbach, 2009),

- create cognitive conflict (Chen, Lien, Annetta \& Lu, 2010),

- can improve and enhance visual-spatial perception ability (Greenfield, Brannon \& Lohr, 1994; Lee \& Peng, 2006),

- can generate various competencies (such as motor, cognitive, emotional, social, personal, etc.) (Kretschmann, 2010),

- can stimulate intensive mental engagement (Prensky, 2001), and

- create conditions for better memory retention (Oblinger, 2004; Lee \& Peng, 2006).

The most successful and the most common form of educational games are the mini games targeting at preschool age and primary education level children. These games attempt to help young children to obtain basic skills such as numbers, letters, simple maths, and reading, offering entertainment and instruction for their target audience (Kickmeier-Rust, 2009).

Mini games are short computer games with basic rules and are easy to play. They are often completely focused on a concrete concept to be taught (conceptual mini games), in order to transform the game into a learning object. This sub-category of educational games has very simple rules which do not change while playing the game. Therefore, it is easy for the teacher to evaluate the progress of the students (Illanas, Gallego, Satorre \& Llorens, 2008).

One of the first fields where educational games were applied was mathematics education. Considering children's natural love for playing games, the growing availability of electronic media, and the fact that children spend a great deal of time interacting with electronic media (Fisch, Lesh, \& Motoki, 2009), the educational value of digital games is very clear. Nevertheless, there exist quite a few empirical studies relating to questions of exactly how and why children act one way or another within the evolving dynamics of an educational gaming environment (Gee, 2003; Ke, 2008; Conati \& Zhao, 2008; Fisch, Lesh, \& Motoki, 2009). In addition, many researchers contend that the effectiveness of computer games on learning is still unknown (Ke, 2006, 2008).

In the field of mathematics, many researchers propose that digital games are the perfect tools, with great motivational appeal for improving mathematical learning (Conati \& Zhao, 2008; Lee \& Cheng, 2009; Eliens \& Ruttkay, 2009a). Ke (2006) also notes that it seems, from a few empirical studies, that digital games can be effective tools for understanding arithmetical concepts or for problem solving. 
In their study, Ota and DuPaul (2002) examined the effects of using software with a digital game format to improve the maths performance of young students with attention-deficit hyperactivity disorder. The results of their research showed that, to a certain extent, users' performance was improved, while their attention was increased. Balasubramanian and Wilson (2006) analysed the findings of numerous studies and found that well-designed educational digital games and simulations can help students to obtain critical problem-solving and decision-making skills, which are necessary for everyday living.

Kebritchi (2008) and Kebritchi, Hirumi and Bai (2010) indicated a significant improvement in the mathematical skills of participants playing a specific mathematical digital game, compared to those who did not play the computer game. This finding is supported by a number of reasons, which, according to teachers, are:

- the experiential nature of the learning,

- the alternative method of teaching and learning,

- the students dealing with mathematics in order to progress in the game (score),

- the transformation of mathematics phobia to a projection of the relationship between mathematics and real life, and

- the students feeling that they were not working with mathematics concepts.

According to the students, the reasons for the improvement in their mathematical skills were:

- the combination of learning and entertainment,

- the adventurous and exploratory context in which they played with mathematics, and

- the challenge that existed in the game's environment.

In this work, we describe the conceptual mini game named PwN. PwN is a computer game aiming to improve students' skills in simple mathematic operations such as the addition of integers, the addition of decimals and the multiplication of integers in a competitive environment. Using a sample of 33 students of the fifth grade of a primary school, we attempted to explore the factors affecting the game's use and collect feedback for several aspects of the application.

\section{Description and Implementation of PwN}

$\mathrm{PwN}$ is an educational game (a conceptual mini game) implemented with Microsoft VB 6.0 using Microsoft Windows (7 or XP). It is modular, enabling the integration of a main module that consists of independent components with differentiated content and diverse educational goals.

The general concept of the application is described below:

- From the teacher's perspective: The teacher defines a specific number standing for the sum or the product to be achieved, through the configuration panel. The teacher also defines the operational features of the game, which will be described later in this section.

- From the student's perspective: In a window on the screen there is a box with specified dimensions. When the game starts, pictures with random numbers fall continuously from the top of the window towards the box. The user can relocate each falling number moving it left or right, in order to place it on an appropriate stack in the box. The objective is to create stacks with numbers, whose sum or product is equal to the predefined number. The score rises when the user manages to create predefined sums or products using a group of consecutive numbers of the same stack. Every successful effort is followed by characteristic sounds.

Figure 1 depicts an instance of the application during run time. On the left side of the window and from top to bottom the following features are illustrated: player's name, score, elapsed time and the total amount of numbers contained in the box. On the top right of the screen lies the button that enables the configuration of several operational features by the educational administrator. User access is personalized (login with username). The button lying below the application configuration button enables the user to enter his name in order to start the game.

$<$ Figure 1 about here $>$

The game's starting button is in the middle of the right side of the screen illustrated in Figure 1, while the exit button is located at the bottom right of the screen. Under the box there are three buttons. The left and the right buttons are used to horizontally relocate the falling numbers, while the middle button is used for pausing/restarting the game.

The application's operation depends on several features concerning the sum or the product to be achieved, the bounds and the kinds of numbers to be used, as well as features relative to the speed of the falling numbers, the duration of the game and the capabilities for recording the user's actions. The administrator is able to adjust, through the configuration panel, the following features:

- The requested sum or product that has to be achieved. 
- The bounds (range) of addends or factors that will be randomly used by the application.

- Whether the user will have to create a specific sum or product through a predefined amount of addends or factors (varying from 2 to 5 ).

- The number that initiates the production of sequences of random numbers.

- The speed with which the numbers fall (movement step in pixels/ms and movement's period).

- The game's duration. This may be unlimited or limited to a defined amount of time.

- Whether detailed user information will be recorded or only basic information, such as full name and total score.

The speed at which the numbers fall is adjustable, but remains stable while playing the game. The administrator can adjust the numbers' falling speed through the configuration panel, though it remains stable regardless of computer power, monitor or display adapter's performance. In the context of this research, the numbers' falling speed was designated at approximately 120 pixels/s, through a pilot test that was performed with a small group of seven students of the fifth grade of a primary education school. This group of students did not participate in the main evaluation group of the PwN application. The determination of this specific falling speed was based on a criterion that depended on two variables:

(a) the minimum required time that the student needed to react and appropriately relocate a falling number aiming to raise his score, and

(b) the student's feeling that the fall was not performed too slowly to cause him to become bored.

It has to be mentioned that inferences from the pilot test were drawn while the box depicted in Figure 1 was empty, meaning that the game was in its initial stages. At this point, the stacks are short and the student has more time to react than at more advanced stages of the game. Naturally, as the game evolves and the stacks grow higher, the user's available reaction time becomes shorter. For this reason, there is no need to increase the falling speed of the numbers either proportionally to the score or the game's duration.

PwN meets all the specifications of a mini game, and like every mini game, there is no definite end to the game. The box can hold $10 \times 10$ (rows x columns) of stacked numbers. The game continues as long as the box is not covered with 100 (10 x 10) numbers, at which point there is no room left for another number. The player's score keeps rising while he achieves predefined sums or products and the box is not completely full of numbers. As supported by llanas, Gallego, Satorre and Llorens (2008), this is probably the most attractive characteristic in this kind of game, because it encourages players to beat themselves. In each game, players try to surpass their previous score.

\section{Methodology - Experimental Setup}

PwN was installed in the computer laboratory of a typical urban school of primary education. The school's computer lab had 12 personal computers (CPU Intel 2,8 GHz / 2 MB RAM) running under a Microsoft Windows 7 operating system with LCD/TFT 17" displays with 1024x768 pixels screen resolution. The falling speed of the numbers was set in all 12 PCs to be equal to the optimum speed inferred by the pilot test.

Participants were selected using a random number generator. Overall, 33 out of 57 students attending the fifth grade were selected for the evaluation of the PwN application. Each student played the game individually in the peaceful environment of the school computer lab. Throughout the experimental procedure the students were observed by at least one researcher, who was responsible for the collection of the experimental data.

During the experimental procedure, the evaluation sample used the PwN application, addressing three arithmetic operations: addition of integers, addition of decimals and multiplication of integers. In order to address each arithmetic operation through $\mathrm{PwN}$, every student was given five minutes for each one. The experimental procedure involved four successive sessions (performed within two weeks), which involved all three arithmetic operations. The total time of each session was 15 minutes and the students had to reach the target sums or products as set by the researcher of each operation. Thus, for the addition of integers, participants were asked to achieve a predefined sum of 10,12, 15 and 18 for each session respectively. For the addition of decimals the target sum was 1.0, 1.4, 1.6 and 1.8 for each session respectively. Finally, for the multiplication task, the target product was 12, 18, 24 and 30 for each session respectively.

Just before the experimental procedure (for competitive reasons) the students were informed that a collection of data regarding their scores would take place. This research is not focused on the exploration of the learning effects of PwN, however, since this has already been performed in a previous study regarding PwN (Panagiotakopoulos, Sarris \& Koleza, 2011).

After the end of the experimental procedure, the students were asked to complete a questionnaire for the application's evaluation. This contained several questions aimed at collecting the students' views concerning:

- the application's ease of use, 
- the application's aesthetics and elements (e.g. colours) they most liked,

- $\quad$ the abilities they had (e.g. self-evaluation) while executing arithmetic operations,

- the creation of a hierarchy of the kind of arithmetic operations that puzzled them the most, and

- $\quad$ the application's effectiveness, i.e. whether and how much they believed that the application improved their performance while executing arithmetic operations.

After the completion of the questionnaires, the researcher had a recorded conversation with each group of students that participated in this research. This conversation aimed to collect information regarding the students' attitudes towards the application. Moreover, the teachers of the students that comprised the evaluation sample were asked to provide data regarding the students' performance in mathematics, as recorded in the personal grade book of each student. This information was used in order to compare their views upon specific issues (discussed in Section 5) with objective data.

\section{Results and Discussion}

The sample consisted of 33 students, of which 18 were boys (54.5\%) and 15 were girls (45.5\%). The sample’s average age was 9.59 years. Every student had a computer at his/her home and they stated they used it for an average of 3.02 hours per week ( $\sigma=1.71$ hours per week). According to the students' answers to relevant questions, they mainly focused on educational games and Internet surfing $\left(\mathrm{x}^{2}=12.3\right.$; $\mathrm{df}=4$; $\left.\mathbf{p}<.05\right)$.

The evaluation sample was asked to express its opinion regarding the ease of use of the application. Their answers were recorded through the five-grade Likert scale (1=Very easy, 2=Easy, 3=Neutral, 4=Difficult, 5=Very difficult). Each answer's frequency is depicted in Table 1.

$<$ Table 1 about here>

As we may observe from Table 1, the application did not raise any difficulties regarding its use. This observation makes sense if we consider that the game play is based only on the arrow keys. Nevertheless, the conversation between researchers and students showed that some of the students associated the application's ease of use with ease of achieving a good score.

A Mann-Whitney U test was conducted to check for presumable differences among gender. The results of the test were as expected and non significant $(\mathrm{z}=.0 ; \mathrm{p}>.05)$. Both boys and girls had an average rank of 17.0 in the ease of use variable.

When the sample was asked to select the most attractive factor of the application among score, ease of use, animation and aesthetics-colours, the Friedman's test analysis revealed statistically significant differences $\left(x^{2}=21.76\right.$; $\mathrm{df}=3$; $\mathbf{p}$ $<$.001). Table 2 shows the mean rank for every factor.

$<$ Table 2 about here $>$

The most attractive factor for the students that participated in the application's evaluation was the score achievement. Essentially, high score achievement (i.e. the competitiveness factor) created the strongest motivation for using PwN.

According to Eliens and Ruttkay (2009b), educators continuously face the problem of motivating their students to learn, and this is particularly true of educators of mathematics. In the present case, the competition that emerged through the struggle to achieve a high score seemed to be helpful regarding the engagement of the student with the execution of arithmetic operations. This very characteristic, when combined with ease of use, may play an important role in engaging students in the learning process that aims to improve their mathematical calculation skills through simple addition and multiplication tasks.

Another analysis showed that the boys liked the animation more than the girls $\left(\mathrm{x}^{2}=8.7\right.$; $\mathrm{df}=3$; $\mathbf{p}<.05$; Cramer's $\mathrm{V}$ $=.51)$. On the other hand, there were no gender differences in the selection of score achievement as the most attractive factor $\left(\mathrm{x}^{2}=2.41\right.$; $\left.\mathrm{df}=3 ; \mathbf{p}>.05\right)$.

There were statistically significant differences when the sample was asked to select the factor that raised the most difficulties while using the application (Friedman's $x^{2}=49.47$; df $=3$; $\mathbf{p}<.001$ ). Table 3 presents the mean rank of each factor.

<Table 3 about here $>$

Table 3 shows that the evaluation sample considered the numbers' falling speed as the factor that raised the most difficulties. A further statistical analysis showed that there were no gender differences concerning the numbers' falling speed factor $\left(\mathrm{x}^{2}=2.1 ; \mathrm{df}=2 ; \mathbf{p}>.05\right)$. Conversely, mathematical tasks raised more difficulties for the girls than for the boys $\left(\mathrm{x}^{2}=14.85 ; \mathrm{df}=2 ; \mathbf{p}<.005\right.$; Cramer's $\left.\mathrm{V}=.67\right)$. It is remarkable, therefore, that the girls stated that the application proved helpful in enhancing their skills in mathematical calculation tasks $\left(\mathrm{x}^{2}=15.04 ; \mathrm{df}=4 ; \mathbf{p}<.01 ; \mathrm{Cramer}\right.$ 's V $\left.=.71\right)$. 
Nevertheless, it should be mentioned that the difficulty students faced concerning the numbers' falling speed, may also constitute an attractive factor for using PwN. Investigating this issue more thoroughly, it is evident that the numbers' falling speed raises difficulties and makes the game more challenging in achieving the goal (which is essentially the achievement of a high score). Meanwhile, it makes the user stay alert due to the fact that simple arithmetic operations have to be executed as fast as possible, creating conditions of action. According to Malone (1981), action alone is a strong factor of attraction.

The same analysis showed that the boys disliked the time limitation regarding PwN's use more than the girls did. Obviously, the boys wanted to play for longer $\left(x^{2}=14.18\right.$; $\mathrm{df}=3 ; \mathbf{p}<.005$, Cramer's $\left.\mathrm{V}=.66\right)$.

The sample was also asked to create a hierarchy of the three arithmetic operations (i.e. addition of integers, addition of decimals and multiplication of integers) according to their difficulty (self-evaluation). The analysis of the received feedback showed a statistically significant difference regarding the most difficult operation (Friedman's $\mathrm{x}^{2}=30.97$; $\mathrm{df}=$ $2 ; \mathbf{p}<.001)$. Table 4 illustrates the mean rank of each operation.

$<$ Table 4 about here $>$

Table 4 shows that the evaluation sample considered the addition of decimals to be the most difficult arithmetic operation. It has to be noted though, that the boys who found the addition of decimals to be the most difficult operation also stated that the application proved to be quite helpful in improving their skills in the execution of this arithmetic operation ( $\mathrm{x}^{2}=18.0$; $\mathrm{df}=3 ; \mathbf{p}<.001$; Cramer's V = .98).

In a further data analysis, the personal grade book of each participant in the evaluation sample was used, and a median split was performed to classify children into high and moderate-low mathematical achievers. From the sample's feedback for each relative question, it emerged that the low mathematical achievers claimed that PwN helped them a lot (to a very great extent or to a great extent), while the high mathematical achievers stated that they were moderately helped $\left(x^{2}=17.8 ; \mathrm{df}=3 ; \mathbf{p}<.001\right.$; Cramer's $\left.\mathrm{V}=.73\right)$. This means that the moderate-low mathematical achievers believed they were helped more from $\mathrm{PwN}$ than the high mathematical achievers did.

Trying to investigate whether there existed a cohesion between the subjective views of the sample regarding their mathematical calculation skills and the objective data emerging from their personal grade books, the nonparametric Spearman correlation was implemented. The analysis showed high cohesion between students' opinions about their mathematical calculation skills and their actual mathematical performance as recorded by their teachers (Spearman's rho $=.61 ; \mathrm{p}<.001)$. This finding leads to the conclusion that the sample's statements are characterized by a high degree of validity.

Next, the sample's students were asked to provide feedback regarding what they disliked while using PwN. Their answers are depicted in Table 5.

$<$ Table 5 about here>

The results shown in Table 5 reinforce the aforementioned conclusion according to which the application creates an increased desire for gaming without time limitations, since the short duration did not please the participants. A secondary problem concerned the numbers' falling speed was that it was directly associated with the achievement of a high score. The sample naturally believed that by using a slower falling speed, it would achieve a higher score.

Finally, several observations emerged from the group conversations between researchers and the students in the sample at the end of the experimental procedure. The three most important observations are summarized in the following list:

- $\quad$ The majority of the students expressed a strong desire to use the application again.

- The game's time limitation was a feature that most of the students disliked. As many of them stated, they would have liked to have been able to play until the game was completed.

- Many of the students manifested a strong desire to use similar score-recording applications in other lessons of the school's timetable as well.

The results of a previous study (Panagiotakopoulos, Sarris \& Koleza, 2011) showed that PwN can help students improve their calculation skills in simple addition and multiplication tasks. For evaluation purposes, the performance of 30 primary school children on three arithmetic operations was examined. In the context of this study, pre- and post-evaluation assessment tests were carried out to examine skills in simple addition (of both integers and decimals) and multiplication. Between these two assessment tests, the main evaluation procedure was performed, where the participants completed three successive practice sessions that involved the practising of all three mathematical operations. Data analysis revealed a substantial increase in students' performance for all arithmetic operations. The gains in calculation skills by the end of the third session were over $22 \%$ for the addition of integers and over $15 \%$ for the 
addition of decimals. A profound difference of $46 \%$ between the initial and the final sessions was observed in the multiplication operation. In an effort to further examine the effect of the PwN application in improving children's calculation skills, we went on to analyse the pre- and post-evaluation assessment test data. Results indicated that in the post-evaluation assessment test, mean accuracy scores were significantly higher than those achieved in the initial testing.

\section{Conclusions}

Many educators and researchers explore methods to deliver content to their students through flexible, convenient, and effective learning techniques. One of these is the use of educational games. Exploiting educational games is not a new method, but many researchers still try to examine various aspects that remain unexplored (Conati \& Zhao, 2008; Fisch, Lesh, \& Motoki, 2009). One issue under investigation concerns the reasons and the manner in which their usage creates conditions that favour learning. Another important issue involves the reason why they inspire such strong motivation to use them, and the precise nature of this motivation.

As Klenowski and her collaborators mention, mathematics is an area that particularly lacks student enthusiasm (Klenowski, Tobias, Funnell, Vance, \& Kaesehagen, 2010). The last 25 years have seen increasing efforts to create effective learning environments through the use of educational games. The aim of these games is to present various concepts in a more appealing way, to make them more concrete, and to reduce potential phobias concerning mathematics (Scanlon, Buckingham \& Burn, 2005).

In this study, a sample of 33 students attending the fifth grade of a primary school was used. All of the students in the sample had a computer at home and used it recreationally, mainly for educational games and Internet surfing.

The findings of the present study indicate that the educational game, which in a previous study has shown to have a positive effect towards improving students' computational skills, is both attractive and motivational for students to use. It should be noted that one of the most cited reasons for using games in educational contexts is that they motivate children (Owen, 2007).

The attraction, in the present case, probably owes its existence to the creation of competition to achieve a high score. But to achieve a high score in $\mathrm{PwN}$, a user needs to perform the correct theoretical calculations before stacking the falling numbers. This essentially means that the gaming environment promotes fast calculation, while directly showing the results of the user's choices. Meanwhile, the application does not raise any difficulties in its use, thus making the challenge of achieving a high score more appealing, since success depends only on the cognitive choices of the user and not on any application-dependent factor.

The analysis of the evaluation data showed that the application was easy to use, without any statistically-important gender differences. In addition, the most attractive factor according to the evaluation sample, was the score achievement. The combination of the above-mentioned factors appeared to be quite helpful for the students in improving their mathematical calculation skills in simple addition and multiplication tasks.

The factor that raised the most difficulties while using PwN (with no statistically significant gender differences) was the numbers' falling speed. Nevertheless, the numbers' falling speed is connected with the user's readiness and score achievement, which was the most attractive factor (according to the evaluation sample). The sample also wanted to play with PwN for longer than the time allotted to them; this was supported more by the boys than the girls.

The analysis with nonparametric Spearman correlation showed high correlation between students' opinions about their mathematical calculation skills and their actual skills, as revealed in their personal grade books. Thus, it appears that what students state with regard to mathematics is characterized by a high degree of validity.

A further analysis was performed, where the students in the sample were classified through a median split into high and moderate-low mathematical achievers using data from their personal grade books. The feedback received through an appropriate question showed that moderate-low mathematical achievers believed they were helped more through the use of PwN than high mathematical achievers.

It can be concluded that educational games provide motivation and opportunities for learning meta-skills and curriculum content, views which are also supported by Owen (2007). The findings from this study show that students would benefit from educational games and would be happy to work within an environment that motivated them and indirectly forced them to deal with mathematical tasks while playing.

However, despite the aforementioned encouraging results, we should be cautious. It is considered that future longitudinal research in the field should address two important questions: the first concerns whether these applications have lasting effects on enhancing children's mathematical calculation skills, whilst the second should focus on the applications' efficiency in positively changing students' attitudes toward mathematical thinking (Scanlon, Buckingham \& Burn, 
2005).

Both the encouraging results obtained from the evaluation study and students' positive opinions lead us to extend the PwN application adding new modules (e.g. singed numbers). A follow-up study is already in progress, focusing on strategies applied by users during mathematical computation.

\section{References}

Amr, K. (2007). Constructing knowledge through games: Essential factors for an effective educational game. In C. Montgomerie \& J. Seale (Eds.), Proceedings of World Conference on Educational Multimedia, Hypermedia and Telecommunications 2007 (pp. 1601-1609). Chesapeake, VA: AACE.

Annetta, L., Murray, M., Laird, S., Bohr, S., \& Park, J. (2006). Serious games: Incorporating video games in the classroom. Educause Quarterly, 3, 16-22.

Balasubramanian, N., \& Wilson, B.G. (2006). Games and simulations. In C. Crawford et al., (Eds.), ForeSITE, Vol. 2005, Proceedings of Society for Information Technology and Teacher Education International Conference 2006. Chesapeake, VA: AACE. [Online] Available: http://site.aace.org/pubs/foresite/ (October 12, 2010).

Chen, H.-P., Lien, C.-J., Annetta, L., \& Lu, Y.-L. (2010). The influence of an educational computer game on children's cultural identities. Educational Technology \& Society, 13(1), 94-105.

Conati, C., \& Zhao, X. (2004). Building and evaluating an intelligent pedagogical agent to improve the effectiveness of an educational game. In Proceedings of the 9th International Conference on Intelligent User Interface, 6-13.

Eliens, A., \& Ruttkay, Z. (2009a). Math games: An alternative (approach) to math education? In 10th International Conference on Intelligent Games and Simulation, GAME-ON 09, 26-28.

Eliens, A., \& Ruttkay, Z. (2009b). Record, replay \& reflect: A framework for serious gameplay. In Proceedings of EUROMEDIA 2009, Brugge (Belgium).

Felicia, P. (2009). Digital games in schools: A handbook for teachers. Belgium: European Schoolnet.

Fisch, S.M., Lesh, R., \& Motoki, E. (2009). Exploring children’s mathematical reasoning when playing online mathematical games. In S.L. Swars, D.W. Stinson, \& S. Lemons-Smith (Eds.), Proceedings of the 31st Annual Meeting of the North American Chapter of the International Group for the Psychology of Mathematics Education, 1489-1496.

Garris, R., Ahlers, R., \& Driskell, J.E. (2002). Games, motivation, and learning: A research and practice model. Simulation \& Gaming, 33(4), 441-467.

Gee, J. P. (2003). What video games have to teach us about learning and literacy. New York, NY: Palgrave-MacMillan.

Graesser, A., Chipman, P., Leeming, F., \& Biedenbach, S. (2009). Deep learning and emotion in serious games. In U. Ritterfeld, M. Cody, \& P. Vorderer (Eds.), Serious Games: Mechanisms and Effects (pp. 81-100). New York: Routledge.

Greenfield, P.M., Brannon, D., \& Lohr, D. (1994). Two-dimensional representation of movement through three-dimensional space: The role of video game expertise. Journal of Applied Developmental Psychology, 1, 87-103.

Habgood, M. P. J. (2007). The effective integration of digital games and learning content. PhD Thesis. UK: University of Nottingham.

Hodgson, P., Man, D., \& Leung, J. (2010). Managing the development of digital educational games. Proceedings of 2010 IEEE International Conference on Digital Game and Intelligent Toy Enhanced Learning, 191-193.

Illanas, A.I., Gallego, D.F., Satorre, C.R., Llorens, L.F. (2008). Conceptual mini-games for learning. IATED International Technology, Education and Development Conference, Valencia (Spain). [Online] Available: http://rua.ua.es/dspace/bitstream/10045/8495/1/illanas08conceptual.pdf (January 12, 2011).

Jeong, E.J., Park, N., Ryu, S., \& Lee, K.M. (2008). Effects of interactivity in serious educational games. Paper presented at the Annual Meeting of the International Communication Association, TBA, Montreal, Quebec, Canada. [Online] Available: http://www.allacademic.com/meta/p234281_index.html (January 12, 2011).

Ke, F. (2006). Classroom goal structures for educational math game application. Proceedings of 7 th International Conference on Learning Sciences (ICLS 2006), ACM Press, 314-320. 
Ke, F. (2008). Computer games application within alternative classroom goal structures: cognitive, metacognitive, and affective evaluation. Education Tech Research Dev, 56, 539-556.

Kickmeier-Rust, M. D. (2009). Talking digital educational games. In M.D. Kickmeier-Rust (Ed.), Proceedings of the 1st International Open Workshop on Intelligent Personalization and Adaptation in Digital Educational Games, 55-66.

Kirriemuir, J., McFarlane, A. (2004). Literature review in games and learning. FutureLab Series, Report 8. [Online] Available: www.futurelab.org.uk/research/lit_reviews.htm (December 11, 2010).

Klenowski, V., Tobias, S., Funnell, B., Vance, F., \& Kaesehagen, C. (2010). Culture-fair assessment: challenging Indigenous students through effortful mathematics teaching. In: AARE International Education Research Conference, 28 November - 2 December 2010, Melbourne. [Online] Available: http://eprints.qut.edu.au/39326/ (January 12, 2011).

Kretschmann, R. (2010). Developing competencies by playing digital sports-games. US-China Education Review, 7(2), 67-75.

Kebritchi, M. (2008). Effects of a computer game on mathematics achievement and class motivation: An experimental study. PhD Thesis. University of Central Florida, Orlando, Florida.

Kebritchi, M., Hirumi, A., \& Bai, H. (2010). The effects of modern mathematics computer games on mathematics achievement and class motivation. Computers \& Education 55, 427-443. doi:10.1016/j.compedu.2010.02.007, http://dx.doi.org/10.1016/j.compedu.2010.02.007

Lee, C., \& Cheng, M. (2009). A computer game as a context for non-routine mathematical problem solving: The effects of type of question prompt and level of prior knowledge. Computers \& Education, 52, 530-542. doi:10.1016/j.compedu.2008.10.008, http://dx.doi.org/10.1016/j.compedu.2008.10.008

Lee, K. M., \& Peng, W. (2006). What do we know about social and psychological effects of computer games? In P. Vorderer \& J. Bryant (Eds.), Playing Video Games: Motives, Responses, and Consequences (pp. 325-345). Mahwah, NJ: Lawrence Erlbaum Associates.

Malone, T. W., and Lepper, M. R. (1987). Making learning fun: A taxonomy of intrinsic motivations for learning. In R. E. Snow \& M. J. Farr (Eds.), Aptitude, Learning, and Instruction: Cognitive and Affective Process Analyses, Vol. 3, (pp. 223-254). Hillside, NJ: Lawrence Erlbaum Associates.

Oblinger, D. G. (2004). The next generation of educational engagement. Journal of Interactive Media in Education, 8, $1-18$.

Oblinger, G. D. (2006). Games and learning: Digital games have the potential to bring play back to the learning experience. Educause Quarterly, 29(3), 5-7.

Ota, K. R., \& DuPaul, G. J. (2002). Task engagement and mathematics performance in children with attention-deficit hyperactivity disorder: Effects of supplemental computer instruction. School Psychology Quarterly, 17(3), $242-257$. doi:10.1521/scpq.17.3.242.20881, http://dx.doi.org/10.1521/scpq.17.3.242.20881

Owen, M. (2007). Why use computer games in education? Proceedings of the 4th Symposium "Designing the School of Tomorrow: Advanced Technologies in Education”, 61-70.

Panagiotakopoulos, C., Sarris, M., \& Koleza, E. (2011). Playing with numbers: Development issues and evaluation results of a computer game for primary school students. International Joint Conferences on Computer, Information, and Systems Sciences, and Engineering (CISSE 10), December 3-12, 2010.

Pivec, M., \& Kearney, P. (2007). Games for learning and learning from games. Informatica 31, 419-423.

Prensky, M. (2001). Digital game-based learning. New York: McGraw-Hill.

Royale, K., \& Clarke, R. (2003). Making the case for computer games as a learning environment. University of Wolverhamption and DESQ. [Online] Available: www.desq.co.uk/doomed/pdf/Making_the_case.pdf (January 12, 2011).

Scanlon, M., Buckingham, D., \& Burn, A. (2005). Motivating maths? Digital games and mathematical learning. Technology, Pedagogy and Education, 14(1), 127-140. doi:10.1080/14759390500200187, http://dx.doi.org/10.1080/14759390500200187

Schiffler, A. (2006). A heuristic taxonomy of computer games. [Online] Available: http://www.ferzkopp.net/joomla/content/view/77/15/ (October 12, 2010) 
Siwek, S. E. (2007). Video games in the 21st century: Economic contributions of the US entertainment software industry. Entertainment Software Association. [Online] Available: http://www.theesa.com/facts/pdfs/VideoGames21stCentury.pdf (January 12, 2011)

Srinivasan, V., Butler-Purry, K., \& Pedersen, S. (2008). Using video games to enhance learning in digital systems. FuturePlay, 196-199.

Virvou, M., Katsionis, G., \& Manos, K. (2005). Combining software games with education: Evaluation of its educational effectiveness. Educational Technology \& Society, 8(2), 54-65.

Yanhong, W., Liming, L., \& Lifang, L. (2010). The innovation of education brought forward by educational games. Proceedings of $2^{\text {nd }}$ International Workshop on Education Technology and Computer Science, 620-622. doi:10.1109/ETCS.2010.185, http://dx.doi.org/10.1109/ETCS.2010.185

Whitton, N. (2010). Learning with digital games: A practical guide to engaging students in higher education. New York: Taylor and Francis.

Yusoff, A. (2010). A conceptual framework for serious games and its validation. PhD Thesis, University of Southampton. Faculty of Engineering, Sciences and Mathematics, School of Electronics and Computer Science. [Online] Available: http://eprints.ecs.soton.ac (January 12, 2011).

Table 1. Frequencies and percentage of answers about the ease of use.

\begin{tabular}{|l|c|r|}
\hline Answer & Frequency & Percentage \\
\hline Very easy & 11 & 33.3 \\
\hline Easy & 15 & 45.5 \\
\hline Neutral & 7 & 21.2 \\
\hline Difficult & 0 & 0.0 \\
\hline Very difficult & 0 & 0.0 \\
\hline Total & 33 & 100.0 \\
\hline
\end{tabular}

Table 2. Ranks for score, ease of use, animation and aesthetics-colours.

\begin{tabular}{|l|c|}
\hline Factor & Mean Rank \\
\hline Score & 1.97 \\
\hline Ease of use & 2.24 \\
\hline Animation & 2.42 \\
\hline Aesthetics-colors & 3.36 \\
\hline
\end{tabular}

Table 3. Ranks for mathematical tasks, speed, execution time and ease of use.

\begin{tabular}{|l|c|}
\hline Factor & Mean Rank \\
\hline Speed & 1.24 \\
\hline Execution time & 2.45 \\
\hline Mathematical tasks & 2.97 \\
\hline Ease of use & 3.33 \\
\hline
\end{tabular}


Table 4. Mean rank for the three operations according to their difficulty.

\begin{tabular}{|l|c|}
\hline Factor & Mean Rank \\
\hline Addition of decimals & 1.42 \\
\hline Multiplication of integers & 1.82 \\
\hline Addition of integers & 2.76 \\
\hline
\end{tabular}

Table 5. Sample's answers to the question: "What you disliked while using PwN".

\begin{tabular}{|l|c|c|}
\hline Answer & Frequency & Percentage \\
\hline The short duration of the game & 19 & 57.58 \\
\hline The falling speed that made operations more difficult & 12 & 36.36 \\
\hline No answer & 2 & 6.06 \\
\hline Total & 33 & 100.00 \\
\hline
\end{tabular}

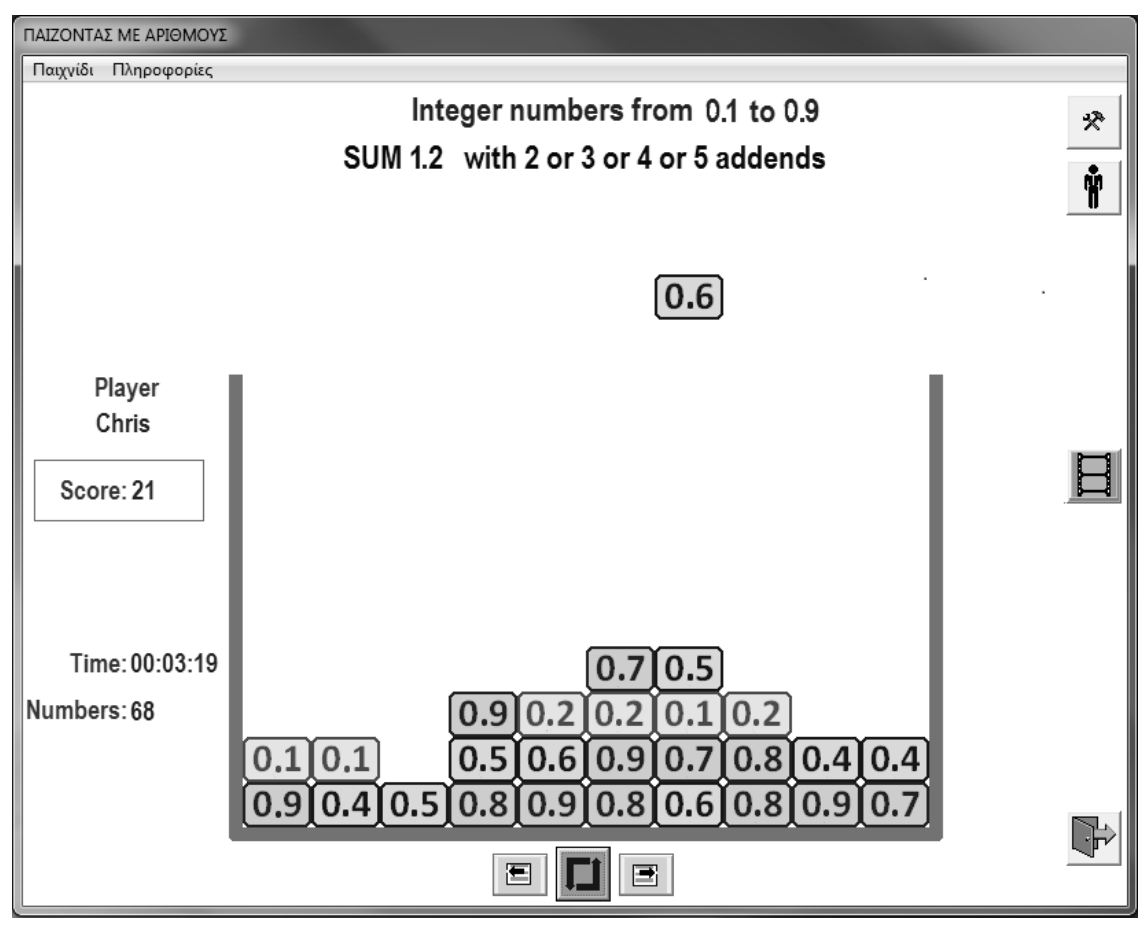

Figure 1. An actual screenshot of PwN for the execution of additions with decimal numbers ranging from 0.1 to 0.9.

\section{Appendix: Questionnaire}

Subject code (filled by the experimenter)

1. Gender $\square$ Male $\square$ Female

2. Date of birth _ $\quad$-'

3. Do you use a computer at home? $\square$ Yes $\square$ No

4. About how many hours per week do you use your computer? __ hours

5. Which do you spend most of your time doing on the computer? (choose best answer)

$\square$ Games 
$\square$ Educational games

$\square$ Surfing the internet

$\square$ Word processing

$\square$ PowerPoint

$\square$ Other (please state)

6. Select one answer from the following, regarding the ease of use of the application.

$\square$ Very easy

$\square$ Easy

$\square$ Neutral

$\square$ Difficult

$\square$ Very difficult

7. Did the application proved helpful in enhancing your skills in mathematical calculation tasks?

$\square$ To a very great extent

$\square$ To a great extent

$\square$ Somewhat

$\square$ To a small extent

$\square$ To a very small extent

8. Select the most attractive factor of the application (only one).

$\square$ Score

$\square$ Ease of use

$\square$ Animation

$\square$ Aesthetics-colours

9. Select the factor that raised the most difficulties while using the application (rank: $1=$ most, $4=$ least).

$\square$ Speed

$\square$ Execution time

$\square$ Mathematical tasks

$\square$ Ease of use

10. Which task is the most difficult for you? (state one of the following).

$\square$ Addition of decimals

$\square$ Addition of integers

$\square$ Multiplication of integers

11. Which of the following mathematical task is the most difficult for you? (rank: $1=$ most, $3=$ least)

$\square$ Addition of decimals

$\square$ Addition of integers

$\square$ Multiplication of integers

12. To what extend do you think you are good at mathematics?

$\square$ To a very great extent

$\square$ To a great extent

$\square$ Somewhat

$\square$ To a small extent

$\square$ To a very small extent 